Jurnal Onoma: Pendidikan, Bahasa dan Sastra

\title{
Nilai dalam Tuturan Adat Sewu Api pada Masyarakat Desa Kelitembu Kecamatan Wewaria Kabupaten Ende
}

\author{
Falentinus Bata \\ Program Studi Pendidikan Bahasa dan Sastra Indonesia \\ Fakultas Keguruan dan Ilmu Pendidikan \\ Universitas Flores \\ Kabupaten Ende, Flores, Nusa Tenggara Timur \\ falentinusbata@gmail.com
}

\begin{abstract}
Abstrak
Peneltian ini bertujuan untuk mendeskripsikan nilai yang terkandung dalam tuturan adat Sewu Api pada masyarakat Desa Kelitembu,Kecamatan Wewaria, Kabupaten Ende. Yang menjadi fokus dalam penelitian ini adalah nilai apa saja yang terkandung dalam tuturan adat sewu api pada masyarakat Desa Kelitembu, Kecamatan Wewaria, Kabupaten Ende. Pendekatan yang digunakan dalampenelitian ini adalah pendekatan kualitatif dengan metode deskriptif. Teknik yang digunakan yaitu teknik catat, teknik rekam, teknik wawancara, dan teknik dokumentasi. Hasil penelitian menunjukkan bahwa dalam tututran adat Sewu Api pada Masyarakat Desa Kelitembu Kecamatan Wewaria Kabupaten Ende ditemukan 10 nilai yakni (1) nilai kepercayaan(2) (2) nilai religius (3) nilai kesuburan (4) nilai keselamatan (5) nilai pengorbanan (6) nilai ketulusan (7) nilai permohonan (8) nilai perlindungan (9) nilai kebersamaan dan (10) nilai larangan atau pantangan. Kata Kunci: Sewu Api, nilai tuturan dan Kabupaten Ende

Abstract

This study aims to determine the values in the traditional utterances of sewu api in the people of Kelitembu Village, Wewaria District, Ende Regency. Sewu api is one of the ceremonies in agriculture which is held every year. The problem raised in this study is what values are contained in the sewu api customary utterances in the people of Kelitembu Village, Wewaria District, Ende Regency? The purpose of this research is to describe the value contained in the sewu api customary utterances in the Kelitembu Village community, Wewaria District, Ende Regency. The approach taken in this research is a qualitative approach, the method used in this research is the description method. The techniques used are note-taking techniques, recording techniques, interview techniques, and documentation techniques. The results showed that in the sewu api customary tututran in the Kelitembu Village Community, Wewaria District, Ende Regency found 10 values, namely (1) the value of trust (2) the value of religious (3) the value of fertility (4) the value of safety (5) the value of sacrifice (6) Sincerity (7) Value of application (8) Value of protection (9) Value of togetherness and (10) Value of prohibition / prohibition.
\end{abstract}

Keywords: Sewu Api, Speech Value and Ende Regency 
Jurnal Onoma: Pendidikan, Bahasa dan Sastra

ISSN 2443-3667

PBSI FKIP Universitas Cokroaminoto Palopo

ISSN 2715-4564

(Print)

(Online)

Volume 7 Nomor 1 Tahun 2021

\section{Pendahuluan}

Bahasa Merupakan alat komunikasi yang unik dan mempunyai pola, bentuk, makna dan perbendaharaan kata yang khas dalam kehidupan sehari-hari. Tanpa Bahasa manusia tidak dapat berbuat apa-apa. Bahasa adalah alat yang ampuh untuk menghubungkan dunia seseorang dengan dunia diluar dari diri kita, dunia seseorang dengan lingkungannya, dunia seseorang dengan alamnya bahkan dunia seseorang dengan Tuhannya (Pateda, 2011: 6). Bahasa pada hakikatnya merupakan suatu sistem simbol yang tidak hanya merupakan urutan bunyi-bunyi secara empiris, melainkan memiliki makna yang sifatnya nonempiris. Dengan demikian bahasa merupakan sistem simbol yang memiliki makna, merupakan alat komunikasi manusia, penuangan emosi manusia serta merupakan sarana pengejawantahan pikiran manusia dalam kehidupan sehari-hari terutama dalam mencari hakikat kebenaran dalam hidupnya (Kaelan, 2002: 7). Bahasa pada umumya merupakan alat komunikasi yang sering digunakan manusia untuk berkomunikasi dengan sesama. Bahasa juga menjadi wadah penyimpanan informasi. Bahasa berkembang secara simbiosis dengan budaya dalam berlangsungnya kehidupan. Bahasa jugaterdapat system tanda yang mewakili sesuatu hal yang dapat menimbulkan reaksi yang sama bila ornag menanggapinya. Bahasa bisa bermakna jika yang diwakilkannya itu beraitan dengan segalah aspek kehidupandan alam sekitar.

Bahasa itu sistematis artinya bahasa itu dapat diuraikan atas satuan-satuan terbatas yang terkombinasi dengan kaidah-kaidah yang dapat diramalkan. Bahasa menjadi media bagi para pengunaanya. Dalam kehidupan sehari-hari manusia sangat tergantung terhadap bahasa untuk bisa berkomunikasi, dan berinteraksi dengan sesama. Menurut Gawen (2017:3) Fungsi dasar bahasa adalah menjadi sarana komunikasi dan perekat antar anggota masyarakat. Oleh karena itu, bahasa menampilkan corak dan karakternya sebagai gambaran identitas manusia. Sebagai pengguna bahasa manusia tentunya menyadari cara menggunakan bahasa sesuai dengan konteksnya, dan situasi yang sedang terjadi. Bahasa itu tidak dipergunakan sembarangan melainkan dipergunakan sesuai konteks yang sedang terjadi. Melalui bahasa seseorang anggota masyarakat perlahan-lahan belajar mengenai segalah adat istiadat, tingkah laku, dan tata karma masyarakatnya. Bahasa menunjukan perbedaan antara satu dengan yang lainnya, tetapi masing-masing tetap mengikat kelompok penuturnya dalam satu kesatuan. Bahasa memungkinkan tiap individu untuk menyesuaikan dengan adat istiadat dan kebiasaan masyarakat bahasa itu (Keraf, 2004: 6)

Bahasa bersifat unik artinya setiap bahasa mempunyai sistem yang khas yang tidak harus ada dalam bahasa lain. Sama halnya dalam bahasa Lio di Kabupaten Ende yang digunakan oleh masyarakat Lio dalam berkomunikasi. Bahasa lio memiliki keunikan tersendiri yang tampak pada dialek penutur dari suku yang berbedah. Bahasa memungkinkan anggota masyarakat mengenal adat istiadat, tingkah laku, dan tata krama budaya dalam masyarakat. Jika dikaitkan dengan dunia sastra, tuturan adat dalam upacara adat memiliki nilai estetis dan magis yang dapat memengaruhi keharmonisan hidup masyarakat, dan sebagai bentuk kontrol bagi polah tingka laku dalam menjalani kehidupan sehari-hari. Tradisi tersebut merupakan warisan leluhur oleh karena itu perlu dipertahankan dan dilestarikan. Tujuan dilaksanakannya upacara adat adalah sebagai penghormatan kepada leluhur, menghidupkan kebudayaan nenek moyang, dan menjunjung asal usul suku.

Bahasa bersifat arbitrer artinya bahasa berubah-ubah, tidak tetap. Arbitrer adalah tidak adanya hubungan wajib antara lambang bahasa yang berwujud bunyi dengan konsep

Halaman | 36 
Jurnal Onoma: Pendidikan, Bahasa dan Sastra

atau pengertian yang dimaksud oleh lambang tersebut (Chaer, 2012:45). Bahasa merupakan bagian dari kebudayaan. Jadi, hubungan antara bahasa dan kebudayaan merupakan hubungan yang subordinatif, di mana bahasa berada di bawa lingkup kebudayaan. Namun, ini bukanlah satu-satunya konsep yang dibicarakan orang, sebab disamping itu ada pendapat lain yang menyatakan bahwa bahasa dan kebudayaan mempunyai hubungan yang koordinatif, yakni hubungan yang sederajat, yakni hubungan sama tinggi. Bahasa dan kebudayaan merupakan dua sistem yang melekat pada manusia, kebudayaan itu adalah satu sistem yang mengatur interaksi manusia di dalam masyarakat, maka bahasa adalah satu sistem yang berfungsi sebagai sarana berlangsungnya interaksi itu (Chaer \& Agustina, 2004:165). Manusia dan kebudayaan merupakan suatu kesatuan yang erat sekali. Dua-duanya tidak dapa dipisahkan. Ada manusia, ada kebudayaan, tidak ada kebudayaan jika tidak ada pendukung ialah manusia.( Soekmono, 1973:10)

Selain sebagai alat komunikasi sehari-hari bahasa juga sebagai bahasa budaya yang dipakai oleh penuturnya untuk mewadahi konsep-konsep budaya daerahnya. Bahasa daerah memungkinkan masyarakat untuk mengenal lebih dekat adat istiadat, tingkah laku, tata, krama, dan budaya dalam hidup bermasyarakat. Bahasa merupakan bagian dari kebudayaan, sering pula disebut sebagai faktor dominan dari kebudayaan bahkan hidup matinya atau maju mundurnya suatu bahasa aspeknya mempunyai hubungan langsung dan terkait pada kebudayaan. Kebudayaan suatu daerah sangat erat hubungannya dengan Bahasa yang digunakan oleh penuturnya.

Bahasa mengenai masyarakat tutur sebenarnya sangat beragam, yang barangkali antara satu dengan yang lainya agak sukar untuk dipertemukan. Bloomfield (Chaer, 2004:37) Membatasi dengan sekelompok orang yang menggunakan sistem isyarat yang sama batasan Bloomfield ini dianggap terlalu sempit terutama dalam masyarakat moderen seperti sekarang ini, banyak orang menguasai lebih dari satu ragam bahasa. Sebaliknya batasan yang diberikan oleh Labov (Chaer, 2004:37) menyatakan dalam satu kelompok orang yang mempunyai norma yang sama mengenai bahasa dianggap terlalu luas dan terbuka untuk memahami lebih jauh dan lebih luas. Dalam upacara adat Sewu Api bahasa yang digunakan adalah bahasa Lio. Bahasa adat ini tidak digunakan sebagai alat komunikasi sehari hari, tetapi bahasa adat hanya bisah digunakan pada saat berlangsungnya upacara adat. Masyarakat Kelitembu merupakan salah satu suku yang mendiami pulau Flores khususnya di Kabupaten Ende, Kecamatan Wewaria.

Upacara Sewu Api merupakan upacara di bidang pertanian yang dilaksanakan setiap tahun setelah tanam padi, jagung, dan lain sebagainya. Upacara Sewu Api adalah salah satu tradisi yang hingga kini masih hidup dan tetap dijalankan oleh masyarakat Kelitembu. Upacara Sewu Api ini dipercayai oleh masyarakat Kelitembu sebagai upacara untuk mengusir hama penyakit yang mendiami kebun pertanian. Pada umumnya tuturan adat tidak dituturkan sebagai alat komunikasi sehari-hari melainkan dituturkan secara khusus pada saat upacara-upacara adat tersebut. Masyarakat Kelitembu masih memegang teguh pada tradisi adatyangtelah diwariskan oleh leluhurnya sehingga tradisi tersebut menjadi cirikhas yang melekat pada kehidupannya. Tuturan adat merupakan unsur bahasa yang menggambarkan budaya suatu masyarakat atau unsur memiliki nilai yang menjadi pedoman dalam aktivitas manusia. Oleh Karena Itu perlu dilakukan penelitian tentang tuturan adat Sewu Api. 
Jurnal Onoma: Pendidikan, Bahasa dan Sastra

\section{Metode Penelitian}

Pendekatan yang dilakukan dalam penelitian ini adalah pendekatan kualitatif. Pendekatan kualitatif merupakan pendekatan yang bertujuan untuk mendeskripsikan secara sistematis dan akurat tuturan pada upacara adat Sewu Api. Data dan sumber data yang digunakan dalam penelitian ini adalah data lisan berupa tuturan adat yang dituturkan oleh tua adat (mosalaki) pada saat berlangsungnya upacara Sewu Api. Metode yang digunakan dalam penelitian ini adalah menggunakan metode deskriptif karena data yang dikumpulkan secara kualitatif yaitu dengan mendeskripsikan wujud bahasa Lio khususnya yang digunakan masyarakat Desa Kelitembu pada saat upacara adat Sewu Api berlangsung.

Untuk mendeskripsikan ungkapan adat tersebut teknik yang digunakan yaitu pertama, teknik catat, yaitu tata cara tuturan adat pada saat upacara Sewu Api berlangsung. Kedua, teknik rekam, yaitu digunakan untuk merekam semua pembicaraan informan pada saat berlangsungnya upacara Sewu Api. Teknik ini akan sangat membantu penulis pada saat analisis data. Ada data-data yang mungkin terlewatkan saat teknik yang pertama maka hasil rekaman dapat diperdengarkan kembali untuk diproses dan dianalisai lebih lanjut. Ketiga, teknik wawancara, yaitu mencari informasi dari narasumber mengenai upacara adat Sewu Api pada Masyarakat Desa Kelitembu Kecamatan Wewaria Kabupaten Ende. Keempat, teknik dokumentasi, yaitu digunakan untuk menggambil gambar pada saat berlangsung-nya upacara adat Sewu Api.

Setelah data terkumpul kemudian data dianalisis, tahap-tahapanya sebagai berikut: mendengarkan kembali hasil rekaman, mencatat semua data hasil rekaman, menerjemahkan secara harafia data rakaman ke dalam Bahasa Indonesia untuk dianaliasis yangterdapat dalam tuturan adat Sewu Api pada masyarakat Desa kelitembu, dan menarik kesimpulan tentang nilai -nilai yang terdapat dalam tuturan adat Sewu Api pada masyarakat Desa Kelitembu.

\section{Hasil Penelitian}

Adapun nilai-nilai dalam tuturan adat Sewu Api pada Masyarakat Desa Kelitembu Kecamatan Wewaria Kabupaten Ende akan diuraikan sebagai berikut:

\section{Nilai Kepercayaan}

Nilai kepercayaan adalah kemampuuan seseorang untuk bertumpu pada orang lain, dimana kita memiliki keyakinan padanya. Kepercayaan merupakan kondisi mental seseorang dan konteks sosialnya.

\section{So.. wengi lima esa kita tu tau sewu api}

Batas kapan lima enam kita antar buat siram api

Enam hari lagi akan dilaksanakan upacara sewu api

Data 1 tersebut adalah sebuah pengumuman yang disampaikan oleh mosalaki 'tua adat' kepada anakalo fai walo bahwa enam hari lagi akan dilaksanakan upacara sewu api. Pada Data 1 di atas pemakaian kata "So "merupakan sebuah seruan untuk memperhatikan sebuah pengumuman. Nilai kepercayan terlihat pada Data 1 pada 'tahap bou tebo' pada kalimat 'Wengi lima esa kita tu tau sewu api' enam hari lagi akan dilaksanakan upacara sewu api. Masyarakat percaya sepenuhnya akan sebuah 
pengumuman yang disampaikan oleh tua adat tentang rencana pelaksanaan upacara sewu api berdasarkan kesepakatan para tua adat

\section{Nilai Religius}

Merupakan nilai yang berhubungan dengan Tuhan yang kudus dan memiliki sifat esamu, sehingga dilakukan pemujaan atau penghormatan kepada-Nya.

\section{Data 2}

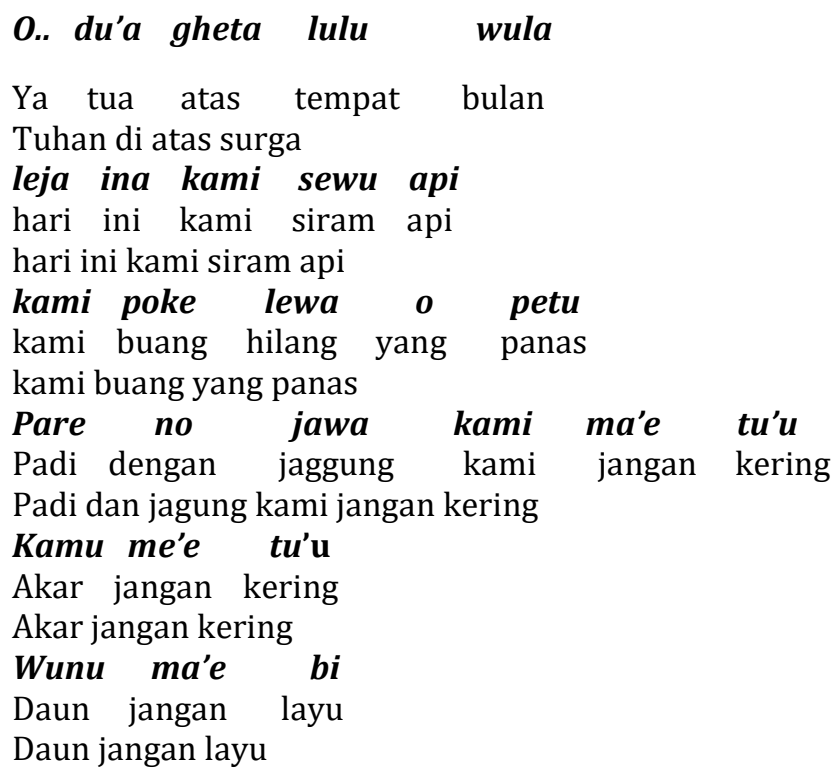

Pada Data 2 tersebut menggambarkan nilai religius masyarakat yang meminta kepada Tuhan, agar Tuhan senantiasa menuntun selama pelaksanaan upacara Sewu Api sehingga dapat berjalan sesuai rencana. Data di atas berupa permohonan dimana mosalaki atau tua adat menyampaikan kepada Tuhan bahwa hari ini mereka melaksanakan upacara sewu api, maksudnya agar Tuhan senantiasa melindungi dan juga menyertai pada setiap rangkaian upacara yang akan mereka lewati sehingga dapat berjalan dengan lancar tanpa ada kendala satupan. Nilai religius terlihat pada kalimat 'o.. du'a gheta lulu wula leja ina kami sewu api' Masyarakat menyampaikan kepada Tuhan bahwa hari ini pelaksanaan upacara sewu api, Masyarakat mengharapkan campur tangan dari Tuhan selama pelaksanaan upacara berlangsung sehingga, dapat berjalan dengan lancar tanpa ada kendala yang menghabat selama melaksanakan upacara sewu api.

\section{Nilai Kesuburan}

Nilai kesuburan merupakan kemampuan seseorang agar dapat menghasilkan yang lebih baik. Nilai kesuburan dapat dilihatnpada Data 2 dalam kalimat "kami poke lewa o petu'pare no jawa kami ma'e. 'Padi dan jagung kami jangan kering 'Kamu me'e tu'u' 'akar jangan kering 'Wunu ma'e bi' 'Daun jangan layu'. Empat kutipan kalimat di atas tersebut bahwa setelah menjelaskan meyakini bahwa segala roh jahat dan hama penyakit yang ada di lahan pertanian sudah tidak ada dan telah dibuang sehingga masyarakat tidak khawatir 
lagi akan ancaman dari roh jahat dan hama penyakit, tanaman pun tetap subur, akar tidak kering, daun tidak layu dan mendapat hasil panen yang melimpah.

\section{Nilai Pengorbanan}

Nilai pengorbanan merupakan sesuatu yang tidak bisa dipaksakan dalam menjalaninya. Nilai-nilai dalam pengorbanan diawali dengan semangat yang tumbuh dari dasar hati tentang sesuatu yang dicita-citakan. Nilai pengorbanan yang terkandung dalam tuturan adat Sewu Api seperti tergambar pada data 4 berikut ini.

Data 4

o.. du'a gheta lulu wula

Ya.. Tuhan atas tempat bulan

Tuhan di atas surga

Kami welu telo
Kami simpan telur
Kami simpan telur

Kami rina pati kami uja

Kami minta kasih kami hujan

Kami minta berikan kami hujan

Data 4 tersebut menggambarkan nilai pengorbanan masyarakat Desa Kelitembu dalam melaksanakan upacara Sewu Api mereka harus menyiapkan bahan sesaji berupa telur, beras, moke, dan ayam. Masyarakat desa Kelitembu dengan rendah hati memberikan pengorbanan berupa telur, beras, moke, dan ayam untuk dijadikan sesaji kepada Tuhan dan nenek moyang. Tujuan mereka hanyalah untuk mendapatkan apa yang mereka inginkan. Nilai pengorbanan dinyatakan dalam kalimat 'kami welu telo kami rina pati kami uja' kami simpan telur. Tuturan tersebut merupakan persembahan yang diberikan oleh masyarakat Kelitembu kepada Tuhan berupa telur yang disimpan di atas bambu agar Tuhan memberikan hujan dan embun kesuburan yang membasahi ladang para petani.

Adapun nilai pengorbanan yang terdapat pada Data 4 dalam tahap pelaksanaan 'tu tau' Data 4:

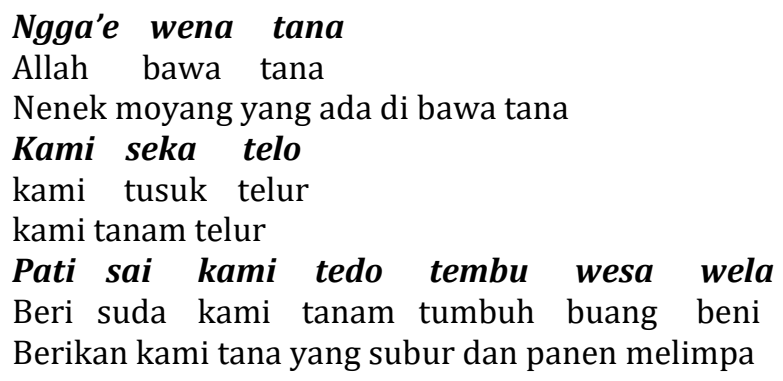

Nilai pengorbanan pada Data 4 di atas menggambarkan persembahan kepada nenek moyang berupa telur yang dikuburkan di dalam tanah. Persembahan ini dilakukan dengan maksud agar nenek moyang menjaga tanaman para petani dari jangkauan hama penyakit sehingga tanaman tetap subur dan mendapatkan hasil panen yang melimpah. 
Jurnal Onoma: Pendidikan, Bahasa dan Sastra

Volume 7 Nomor 1 Tahun 2021

\section{Nilai Ketulusan}

Nilai ketulusan merupakan sebuah pengetahuan tentang kebenaran yang sejati. Setiap hal yang ada pada diri manusia berasal dari Tuhan karena Dia telah terlebih dahulu mengasihi kita maka sudah sepatutnya kita mengasihi-Nya.

Data 5:

Nebuina kami rina ria no ate o masa

Sekarang kami mintah besar dengan hati yang bersih

Sekarang kami minta dengan hati iklas

Leka du'a gheta lulu wula

Kepada tuhan atas tempat bulan

Kepada Tuhan yang ada di atas surga

Pati sai kami tedo tembu wesa wela

Kasih sudah kami tanam geju buang benih

Berikan kami hasil panen melimpah

Data 5 tersebut menggambarkan nilai ketulusan masyarakat dalam berdoa dengan hati yang bersih dan dengan ikhlas kepada Tuhan agar Tuhan senantiasa memberkati segalah usaha mereka dan pekerjaan mereka sehingga mendapat hasil melimpah. Nilai ketulusan dapat dilihat pada kalimat 'Nebuina kami rina ria no ateo masaoso masa' Sekarang ini kami minta dengan hati yang ikhlas, sedangkan dalam kalimat 'Leka du'a gheta lulu wula' Pada Tuhan yang ada di atas surga, sedangkan dalam kalimat 'Pati sai kami tedo tembu wesa wela' berikan kami panen yang melimpah. Tuturan tersebut mau menjelaskan bahwa masyarakat Kelitembu berdoa dan meminta dengan hati yang ikhlas kepada Tuhan di surga agar senantiasa memberkati dan memberikan panen yang melimpah dalam setiap usah mereka.

\section{Nilai Permohonan}

Nilai permohonan merupakan cara untuk meminta bantuan kepada orang lain dan pada Tuhan saat kita berada dalam kesusahan atau penderitaan. Dalam bidang pertanian manusia juga minta bantuan kepada Tuhan agar Tuhan senantiasa memberkati segalah usaha manusia.

Data 6

O.. du'a gheta lulu wula, ngga'e wena tana

Ya.. tua atas tempat bulan Allah bawa tanah

Ya.. tuhan di ats langit dan nenek moyang dibawa tanah

Pati sai kami gaga bo'o kewi ae

Kasih sudah kami kerja kenyang hasil air

Berikan kami hasil yang melimpah yang melimpah

Data 6 tersebut merupakan nilai permohonan kepada tuhan dan nenek moyang. Masyarakat Wolojita berdoa agar tuhan dan Nenek moyang senantiasa memberkati dan melindungi segala usaha para petani agar mendapatkan hasil yang melimpah. Nila permohonan pada Data 6 dapat dilihat dalam ' $O$ du'a gheta lulu wula, ngga'e wena tana' Pada kalimat ini masyarakat memohon kepada Tuhan dan nenek moyang, sedangkan dalam kalimat 'Pati sai kami gaga bo'o kewi ae' Berikan kami hasil panen yang melimpah.

\section{Nilai Keselamatan}

Nilai keselamatan merupakan nilai yang berhubungan dengan terbebasnya manusia dari malapetaka, bencana alam dan penyakit. Nilai keselamatan seperti yang tergambar pada Data 7 berikut ini: 


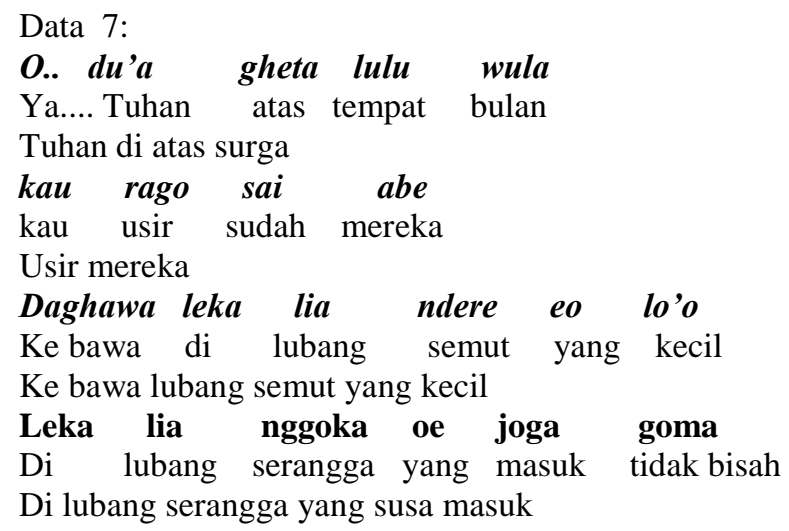

Nilai keselamatan merupakan bagian dari nilai kehidupan. Nilai keselamatan dalam konteks ini adalah nilai yang berhubungan dengan kepercayaan terhadap tuhan yang memberi keselamatan bagi masyarakat Desa Kelitembu. Nilai keselamatan dapat dilihat pada Data 7 dalam kalimat $\boldsymbol{O}$ du'a gheta lulu wula Ya Tuhan yang di atas surga. Pada kalimat ini masyarakat Kelitembu berdo'a kepada tuhan yang telah memberikan kehidupan dan keselamatan dalam hidup Mereka. kau rago sai abe. Usirlah mereka. Kalimat ini menjelaskan masyarakat memohon kepada Tuhan agar mengusir hama enyakit yang menyerang tanaman para petani. Daghawa leka lia ndere eo lo'o ke bawa lubang semut yang kecil Leka lia nggoka oe joga goma di lubang serangga yang tidak bisa Masuk. Isi dari kedua kalimat itu masyarakat meminta kepada Tuhan untuk mengusir hama penyakit agar keluar dari lahan pertanian, sehingga tanaman para petani selamat dari hama penyakit dan bisa menghasilkan panen melimpah.

Masyarakat Kelitembu percaya bahwa dengan berdoa meminta keselamatan pada Tuhan maka tanaman para petani akan dijauhkan dari serangan roh jahat atau hama penyakit sehingga tanaman tetap tumbuh subur dan menghasilkan panen yang melimpah.

\section{Nilai Perlindungan}

Nilai perlindungan merupakan cara seseorang dalam mengatasi masalah yang sedang terjadi atau yang sedang menimpa dirinya. Dalam bidang pertanian, masyarakat perlu memohon perlindungan kepada Tuhan untuk mempertahankan tanamanya dari serangan hama untuk memaksimalkan hasil produksi.

Data (8)

O.. du'a gheta lulu wula
Ya.. tuhan atas tempat langit
Tuhan di atas surga
Jaga we abe temu sai mai
Jaga supaya mereka jangan lagi datang
jaga supaya mereka jangan lagi datang
No gha langi temu sai dari
Dan sini batas jangan lagi berdiri
Di batas kebun jangan berdiri
Gha uma temu sai sula
Di kebun jangan lagi muncul
Jangan lagi muncul di kebun


Data 8 tersebut merupakan nilai perlindungan. Isi Data 8 di atas adalah masyarakat Wolojita berdoa kepada Tuhan agar Tuhan melindungi tanaman para petani dari serangan hama penyakit yang akan merusak tanaman. Nilai perlindungan dapat dilihat dalam kalimat 0 . du'a gheta lulu wula Ya Tuhan di atas surga jaga supaya mereka (hama penyakit) jangan lagi datang, No gha langi temu sai dari di batas kebun jangan lagi berdiri, No gha langi temu sai dari jangan lagi muncul di kebun.

Tuturan adat di atas menggambarkan bahwa masyarakat Kelitembu percaya bahwa berdoa untuk meminta perlindungan kepada Tuhan dapat membantu menjaga tanaman agar terhindar dari serangan hama penyakit dan memperoleh hasil panen yang melimpah

\section{Nilai Kebersamaan}

Nilai kebersamaan merupakan bagian dari budaya yang merupakan tingkatan yang paling abstrak dari adat yang terdiri dari konsep-konsep yang hidup dalam pikiran, sebagian besar dari warga masyarakat mengenai hal-hal yang mereka anggap bernilai dalam hidupnya. Nilai kebersamaan yang terdapat dalam tuturan adat sewu api tergambarkan pada Data 9 dalam tahap pa'a loka berikut ini:

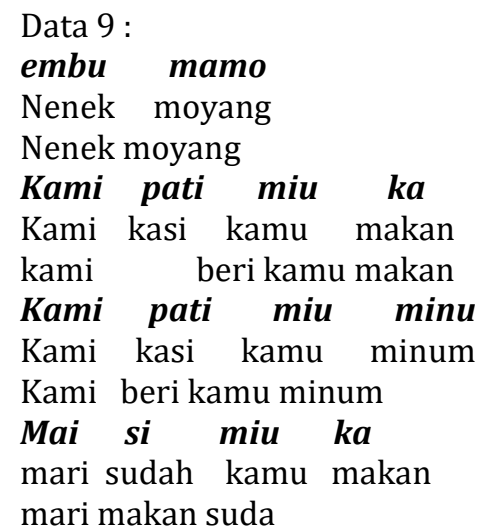

Data 9 tersebut menggambarkan nilai kebersamaan masyarakat yang percaya bahwa nenek moyang ada bersama-sama dengan mereka sehingga mereka memberikan sesajian dan memanggil nenek moyang untuk datang makan dan minum bersama dengan mereka.

\section{Nilai Larangan atau antang}

Nilai larangan/ pantang merupakan ungkapan nasihat larangan dan pantangan untuk melakukan sesuatu yang menurut tradisi dan keyakinan adat istiadat dapat menyebapkan datangnya malapetaka, dampak buruk, dan kesialan.

Data 10

Lele dowa leja ina kita tu tau sawe sewu api

Denggar semua hari ini kita antar buat sudah siramapi

Dengar semua kita sudah selesai upacara siram api

Wesia pire ma,e mbana uma

Besok pemali jangan jalan kebun

Besok jangan pergi kebun

ma'e poka kaju meta

jangan potong kayu mentah

jangan potong kayu

ma'e je leka wewe sa'o

jangan sapu di halaman rumah

jangan sapu di halaman rumah 
Jurnal Onoma: Pendidikan, Bahasa dan Sastra

ma'e koe tana

jangan gali tanah

jangan menggali tanah

Data 10 tersebut menggambarkan nilai larangan/ pantang dimana masyarakat Kelitembu percaya bahwa setelah selesai melaksanakan upacara sewu api masyarakat tidak boleh pergi ke kebun serta melakukan aktivitas seperti, potong kayu, menyapu halaman rumah dan menggali tanah di tanah persekutuan adat Kelitembu. Apabila masyarakat melanggar secara sengaja maupun tidak sengaja maka akan mendapat malapetaka, dampak buruk, dan kesialan. Nilai larangan atau pantangan dapat dilihat pada kalimat 'Wesia pire ma'e mbana uma' besok pemali jangan pergi Kebun. Pada tuturan ini menyampaikan bahwa besok jangan pergi ke kebun. 'ma'e poka kaju mete' jangan potong kayu mentah, kalimat ini berisi larangan supaya jangan memotong kayu mentah 'ma'e je leka wewe $\boldsymbol{s a}^{\prime} \boldsymbol{o}^{\prime}$ jangan menyapu halaman rumah kalimat tersebut berisi larangan supaya jangan menyapu halaman rumah 'ma'e koe tana' jangan gali tanah kalimat tersebut menggambarkan larangan supaya jangan menggali tanah. Larangan ini sebagai bentuk penghormatan kepada leluhur. Apabila masyarakat menggali tanah baik sengaja maupun tidak sengaja, maka telur yang ditanam sebagai persembahan kepada nenek moyang akan merusak tanaman yang melanggar larangan tersebut. Larangan ini berlaku selama satu hari penuh setelah malaksanakan upacara Sewu Api.

\section{Simpulan}

Berdasarkan hasil penelitian maka dapat disimpulkan nilai yang terkandung dalam tuturan adat sewu api pada masyarakat Desa Kelitembu, Kecamatan Wewaria Kabupaten Ende adalah sebagai berikut: nilai kepercayaan, Nilai Religius, Nilai kesuburan, Nilai pengorbanan, Nilai keselamatan, Nilai ketulusan, Nilai permohonan, Nilai perlindungan, Nilai kebersamaan, Nilai larangan atau pantang. Nilai larangan atau pantang merupakan sebagai ungkapan nasihat larangan dan pantangan untuk melakukan sesuatu yang menurut tradisi dan keyakinan adat istiadat dapat menyebapkan datangnya malapetaka, dampak buruk dan kesialan.

\section{Daftar Pusataka}

Chaer, Abdul \& Agustina, Leonie. 2004. Sosiolinguistik Edisi Revisi Cetakan Kedua. Jakarta: Renaka Cipta.

Chaer, Abdul. 2012. Linguistik Umum. Jakarta: Rineka Cipta.

Chaer, Abdul.2004. Sosiolinguistik Perkenalan Awal, Jakarta: Rineka Cipta

Gawen, Alexander Bala. 2017. Pembelajaran Pragmatik, Yogyakarta: Ombak.

Ibrahim , Maulana. 2017. Nilai Moral dalam cerita rakyat Nggera Mbari dan Watu Mite Desa Kerirea Kecamatan Nangapanda Kabupaten Ende.(skripsi) Program Studi Pendidikan Bahasa dan Sastra Indonesia. FKIP Universitas Flores: Ende

Kaelan. 2002. Filsafat Bahasa. Yogyakarta: Paradigma

Keraf, Gorys. 2004. Komposisi, sebuah pengantar kemahiran Bahasa. Ende: Nusa Indah. Pampe, pius. 2009. Pemberdayaan Bahasa Lokal dalam Kegiatan Keagamaan. Kupang:Gita Kasi. 
Jurnal Onoma: Pendidikan, Bahasa dan Sastra

Volume 7 Nomor 1 Tahun 2021

Petade, Mansoer. 2011. Linguistik Sebuah Pengantar. Bandung: Angkasa

Soekmono. 1973. Pengantar Sejarah Kebudayaan Indonesia. Yogyakarta: Kanisius 